\title{
Math and semen analyses cast doubt on Swiss HIV stance
}

Earlier this year, Switzerland's National AIDS Commission shocked scientists and AIDS advocacy groups by issuing a statement condoning unprotected sex among certain couples affected by HIV. But new research now challenges the validity of such advice, fueling the debate over when - if ever — condoms should be abandoned by people with the disease.

According to the Swiss statement, couples in which only one partner is infected with HIV can safely have sex without a condom under certain circumstances. The conditions include that both partners are aware of the situation and that the infected person adheres to a closely monitored regimen of antiretroviral drugs that have suppressed HIV concentration in the blood to a level below 40 copies of the virus per milliliter for at least six months. Importantly, the conditions also require that neither partner has a sexually transmitted disease (STD).

A team of Australian scientists recently used a mathematical model to predict what would happen if 10,000 couples followed such a policy for ten years. The model predicted that HIV incidence would quadruple as compared with if condom usage remained stable (Lancet 372, 314-320; 2008). "I think the take-home message is that over many sex acts, a small risk per act can accumulate, so we should not assume complete protection from ARVs [antiretrovirals]," comments Geoffrey Garnett, an epidemiologist at Imperial College London who was not involved in the research.

The findings defy the Swiss stance, according to the new study's lead author, David Wilson of the University of New South Wales in Sydney. "I believe that it is not a sensible public health message," he says. An HIV blood concentration below 40 viral copies per milliliter is no safeguard against transmission, Wilson adds: "Just because we do not detect the virus in the blood does not mean it's not in other body fluids."

"What's going on in the semen does not always correlate with what's going on in the blood," says Carole Gilling-Smith of London's Chelsea and Westminster Hospital. New research presented by Gilling-Smith and her colleagues earlier this summer at the European Society of Human Reproduction and Embryology meeting in Barcelona suggests that as much as $3.7 \%$ of semen taken from men on long-term antiretroviral regimens with no detectable virus in their blood might contain potentially infectious levels of HIV. "From this study, I think we've challenged the Swiss view," Gilling-Smith says.

Pietro Vernazza, president of the commission that produced the Swiss report, says the panel

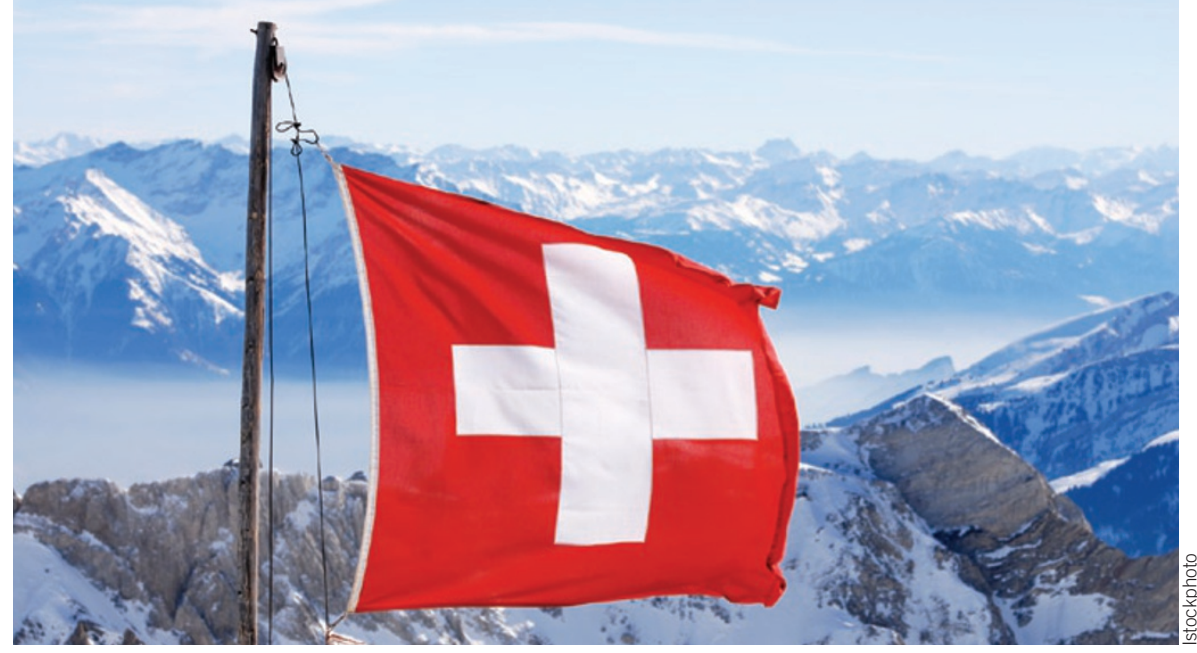

Red flag: Math models predict the Swiss stance could quadruple HIV incidence

took this factor into account. According to Vernazza, if an HIV-positive man taking antiretrovirals has detectable levels of HIV in his semen but not in his blood, chances are he has an STD or he has been taking antiretroviral drugs for less than three months. "We know that STDs are the most important driving force for HIV transmission, outside primary infection, and this is why the Swiss statement clarified, if couples consider having sex without condoms, they should make sure that adherence is perfect and STDs are absent," he says. But Gilling-Smith counters that her study excluded men with STDs, demonstrating that the release of virus can occur in semen despite the absence of STDs and the use of effective antiretroviral therapy.

Garnett remains convinced that, on the basis of the current understanding of HIV, experts should still advocate the concurrent use of condoms and antiretrovirals: "It is important that all the methods of preventing HIV transmission are combined."

Coco Ballantyne, New York

\section{Bigger returns sought on health initiatives}

International aid for health in low- and middle-income nations has doubled over the last five years, and much of the cash flow has come from global health initiatives such as the US President's Emergency Plan for AIDS Relief, according to a recent report by the World Health Organization (WHO). But weaknesses in the health systems of countries receiving aid can limit the potential of these programs, acknowledges the $\mathrm{WHO}$, which recently teamed with the World Bank to address this problem.

"You can give as much money as you want, but [...] without strong health systems we would not achieve our results," says Nicolas Demey of the Geneva-based Global Fund to Fight AIDS, Tuberculosis and Malaria, which has committed $\$ 11.4$ billion over the last six years in its worldwide programs.

The WHO and the World Bank plan to help governments and agencies develop specially tailored approaches to get the most out of global health initiatives. "We will generate new evidence to inform discussions and choices at the country and global levels," explains Olusoji Adeyi, coordinator of public health programs at the World Bank.

But not everyone thinks the WHOWorld Bank partnership is a match made in heaven. Legal expert Amir Attaran of the University of Ottawa contends that the World Bank is not a sensible partner for the WHO. "Having the World Bank involved in health systems and delivery, where the WHO has expertise, is about as logical as your general practitioner calling your banker for a recommendation on what medicine to prescribe," he says. "The best possible solution is to get the World Bank out of this."

Coco Ballantyne, New York 